\title{
Energy Change Regularities of Crystal Lattice of Lanthanide Borohydrides
}

\author{
Mirsaidov U.M. ${ }^{1}$, Gafurov B.A. ${ }^{2}$, Mirsaidov I.U. ${ }^{1}$, Badalov A., ${ }^{2, *}$ \\ ${ }^{1}$ Laboratory of Mineral Raw Materials and Waste Reprocessing, V.I.Nikitin Research Institute of Chemistry Under AS RT, Tajikistan \\ ${ }^{2}$ Faculty of Chemical Engineering and Metallurgy, M.Osimi Tajik Technical University, Tajikistan
}

Copyright $\mathrm{O} 2016$ by authors, all rights reserved. Authors agree that this article remains permanently open access under the terms of the Creative Commons Attribution License 4.0 International License

\begin{abstract}
Thermodynamic characteristics of lanthanides' borohydrides are defined by tensimetric, calorimetric and semiempirical methods. Lanthanides' borohydride crystal energy lattice is defined by compiled Born-Haber cycle and their change regularity within the whole lanthanide's row is determined.
\end{abstract}

Keywords Thermodynamic Characteristics, Lanthanides, Borne-Haber Cycle, Crustal Lattice Energy, Change Regularities, Tetrad-effect

\section{Introduction}

Thermodynamic characteristics - substance formation enthalpy $\left(\Delta_{f} H_{298}^{0}\right)$ and/or Gibbs energy $\left(\Delta_{f} G_{298}^{0}\right)$ are used as criteria for thermodynamic stability of crystal compounds [1-5]. These values are summarized constituent of energy characteristics of multiple intermediate process stages for compounds obtaining. Often these intermediate process stages have big energy characteristics values in comparison with final, additive values.

In such cases, it is difficult to identify crystal compounds stability criteria. For example, energy cycle analysis for carbide, silicide and other compounds formation process [3-6]. Small values of carborundum $\Delta_{f} H_{298}^{0}=-51,9$ $\mathrm{kJ} / \mathrm{mole}$ is due to big energy expenditures and atomization of silicon and carbon crystals but not due to weak binding energy in carborundum (Nat. $=-1255,2 \mathrm{~kJ} / \mathrm{mole}$ ).

\section{Objectives}

In continuation of series of research on thermal and thermodynamic characteristics of complex hydride compounds [7-10], the present work is devoted to enthalpy formation $\left(\Delta_{\mathrm{f}} \mathrm{H}^{0}{ }_{298}\right)$ and crystal lattice energy $\left(\mathrm{U}_{\mathrm{k}}\right)$ identification of complex borohydrides - $\mathrm{Ln}\left(\mathrm{BH}_{4}\right)_{3}$ ( $\mathrm{Ln}$ - lanthanides) and their change regularity determination.

\section{Material and Methods}

Limited literatures are available which cover issues of crystal lattice energy determination of complex hydride compounds. Only works [11, 12] determine crystal lattice energy values for complex boro- and alumohydrides of IA and IIA subgroups elements.

Born-Lande, Born-Mayer, Huggins and other equation use for $U_{k}$ calculation requires availability of many nondescript values, which limits possibilities for these equations application, especially for complicated complex compounds.

Kapustinskiy equation, difference methods and comparative calculation of thermodynamic substance properties, tensimeter, RPA, Poluektov semiemperical method are applied for $\mathrm{U}_{\mathrm{k}}$ determination of lanthanides borohydrides.

Semiempirical equation for approximate $\mathrm{U}_{\mathrm{k}}$ calculation (kilojoule/mole) of any famous or hypothetical ionic compounds proposed by A.F. Kapustinskiy [1], which is expressed by:

$$
\mathrm{U}_{\mathrm{K}}=\frac{1200,5 \cdot \mathrm{V} \cdot \mathrm{Z}_{\mathrm{k}} \cdot \mathrm{Z}_{\mathrm{a}}}{\mathrm{r}_{\mathrm{k}}+\mathrm{r}_{\mathrm{a}}}\left[1-\frac{0,345}{\mathrm{r}_{\mathrm{k}}+\mathrm{r}_{\mathrm{a}}}+0,00435\left(\mathrm{r}_{\mathrm{k}}+\mathrm{r}_{\mathrm{a}}\right)\right]
$$

where: $\mathrm{V}$ - number of ions in one formula unit; $\mathrm{Z}$ - cation or anion charge, and, $\mathrm{r}-$ their radius.

While making calculations by equation (1), where $\mathrm{V}=4$ ion numbers in one formula unit, lanthanide cations $\mathrm{Ln}^{3+}$ radius values are used with coordination number 8 , specific for studying compounds and determined according to X-ray structure investigation of lanthanide borohydride [13-16].

Unknown value for thermochemical radius of $\mathrm{BH}_{4}^{-}$ion in literature is revealed by us according to energy difference of identical crystal lattice of compounds with equal anions, namely alumohydrides and alkali metal borohydrides $[1,2]$. It was equal to $r_{B H_{4}^{-}}=0,23 \mathrm{~nm}$. 
Thermochemical balance of $\operatorname{Ln}\left(\mathrm{BH}_{4}\right)_{3}$ formation can be described by the following Born-Haber cycle:

$$
\begin{aligned}
& {[\mathrm{Ln}]+6\left(\mathrm{H}_{2}\right)+3[\mathrm{~B}] \stackrel{\Delta_{f} H^{0}\left[\operatorname{Ln}\left(B H_{4}\right)_{3}\right]}{\longrightarrow}\left[\operatorname{Ln}\left(\mathrm{BH}_{4}\right)_{3}\right]} \\
& \downarrow \mathrm{S}_{\mathrm{Ln}}+6 \mathrm{D}_{(\mathrm{H} 2)}+3 \mathrm{~S}_{[\mathrm{B}]} \\
& (\mathrm{Ln})+12(\mathrm{H})+3(\mathrm{~B}) \\
& \mathrm{I}_{\mathrm{Ln}}+3 \mathrm{E}_{(\mathrm{H})}+3 \delta_{[\mathrm{BH} 3]} \\
& \left(\mathrm{Ln}^{3+}\right)+3\left(\mathrm{H}^{-}\right)+3\left[\mathrm{BH}_{3}\right] \\
& \mathrm{U}_{\mathrm{K}}\left[\operatorname{Ln}\left(\mathrm{BH}_{4}\right)\right] \\
& \Delta_{f} H\left[\mathrm{BH}_{4}^{-}\right] \longrightarrow \mathrm{Ln}^{3+}+3\left(\mathrm{BH}_{4}^{-}\right)
\end{aligned}
$$

where: Ln - lanthanides; parentheses - gaseous, square brackets - solid state of substance; $S$ - sublimation enthalpy, $D$ - dissociation enthalpy, $\delta$ - formation enthalpy and $E$ sensitivity to component system's electrons.

\section{Results and Their Discussions}

Thermochemical calculations according to Born-Haber cycle are possible in case of data availability for each stage of the cycle. Formation enthalpy value for gaseous borohydride's ion is equal to $\Delta_{f} H_{298\left(B H_{4}^{-}\right)}^{0}=-96,2 \pm 20$ $\mathrm{kJoule} \cdot \mathrm{mole}^{-1}$. Literature data on enthalpy formation value $\left(\Delta_{\mathrm{f}} \mathrm{H}^{0}{ }_{298}, \mathrm{Ln}^{3+}\right)$ for gaseous lanthanides' ion in oxidation level $(+3)[8-10]$ are fragmentary and considerably different. N.S. Poluektov's semiempirical method and others [21, 22] is applied for identification and/or precise value definition $\Delta_{\mathrm{f}} \mathrm{H}^{0}{ }_{298}, \mathrm{Ln}^{3+}$ of gaseous lanthanides' ion. Calculation is carried out according to the following correlation equation:

$$
\begin{gathered}
\Delta_{\mathrm{f}} \mathrm{H}^{0}{ }_{298}, \mathrm{Ln}^{3+}=\Delta_{\mathrm{f}} \mathrm{H}^{0}{ }_{298}, \mathrm{La}^{3+}+\alpha \mathrm{N}_{\mathrm{f}}+\beta \mathrm{S}+ \\
+\gamma^{\prime} \mathrm{S}_{(\mathrm{Ce}-\mathrm{Eu})}\left(\gamma^{\prime \prime} \mathrm{L}_{(\mathrm{Tb}-\mathrm{Yb})}\right.
\end{gathered}
$$

$\alpha$ coefficient - takes into account $4 \mathrm{f}$ - electrons influence, $\beta$ - and $\gamma$ - spin influence (S) - and orbital (L) - lanthanides' atoms and ion motion moments on unknown quantity. $\gamma^{\prime}$ coefficients relates to lanthanides of cerium subgroups, and $\gamma^{\prime \prime}$ - to metals of yttrium subgroup. Equation coefficients values (3), are equal to $\alpha=32,36 ; \beta=-9,00 ; \gamma^{\prime}=9,83$ and $\gamma^{\prime \prime}=4,04$. Calculation results $\Delta_{\mathrm{f}} \mathrm{H}^{0}{ }_{298}, \mathrm{Ln}^{3+}$ of lanthanides' ion are presented in table 1.

$\Delta_{\mathrm{f}} \mathrm{H}^{0}{ }_{298}, \mathrm{Ln}^{3+}$ lanthanides' ion-nature change diagram is presented in Fig. 1.

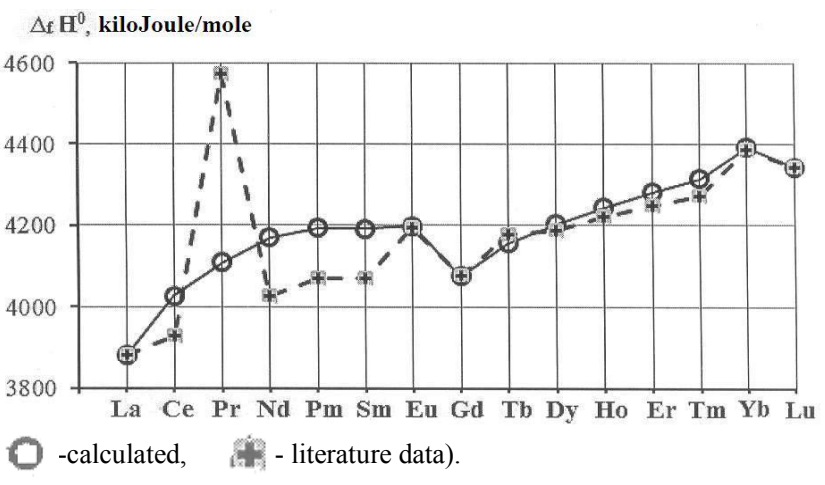

Figure 1. Gaseous lanthanides' ion-nature enthalpy formation change diagram

Diagram has complicated character with clear separation by lanthanide's sub-groups. In cerium sub-group, $\Delta_{\mathrm{f}} \mathrm{H}^{0}{ }_{298}$, $\mathrm{Ln}^{3+}$ value increase is observed with maximum in the middle $\mathrm{Pr}^{3+}$ ion of the subgroup. In yttrium subgroup, almost linear

\begin{tabular}{|c|c|c|c|c|c|c|c|c|c|c|c|c|c|c|c|}
\hline \multirow{2}{*}{$\begin{array}{c}\Delta_{\mathrm{f}} \mathrm{H}^{0}{ }_{298} \\
\mathrm{Ln}^{3+} \\
\mathrm{kJoule} \\
\cdot \mathrm{mole}^{-1} \\
\end{array}$} & \multicolumn{15}{|c|}{ Lanthanides } \\
\hline & La & $\mathrm{Ce}$ & Pr & Nd & Pm & Sm & Eu & Gd & $\mathbf{T b}$ & Dy & Но & $\mathbf{E r}$ & $\mathbf{T m}$ & $\mathbf{Y b}$ & $\mathbf{L u}$ \\
\hline Calculation & 3881 & 3971 & 4018 & 4056 & 4084 & 4102 & 4160 & 4076 & 4157 & 4202 & 4244 & 4281 & 4314 & 4392 & 4334 \\
\hline Literature & 3881 & 3928 & 4571 & 4025 & 4071 & 4071 & 4193 & 4076 & 4176 & 4188 & 4221 & 4247 & 4273 & 4385 & 4334 \\
\hline $\begin{array}{c}\text { Difference } \\
\text { in } \%\end{array}$ & 0,00 & 1,10 & 12,00 & 0,77 & 0,32 & 0,76 & 0,79 & 0,00 & 0,45 & 0,33 & 0,54 & 0,80 & 0,96 & 0,16 & 0,00 \\
\hline
\end{tabular}
symbasis increase of $\Delta_{\mathrm{f}} \mathrm{H}^{0}{ }_{298}, \mathrm{Ln}^{3+}$ value is observed with lanthanide's atomic number increase. Deviation from considered characteristics for $\mathrm{Eu}^{3+}$ and $\mathrm{Yb}^{3+}$ ions is conditioned by their distinct structure with partial and full orbital occupancy by f-electrons. Large values of $\alpha$

\begin{tabular}{|c|c|c|c|c|c|c|c|}
\hline \multicolumn{8}{|c|}{ a) cerium subgroup $\operatorname{Ln}\left(\mathrm{BH}_{4}\right)_{3}$} \\
\hline$L a$ & $\mathrm{Ce}$ & $P r$ & $N d$ & $P m$ & $\mathrm{Sm}$ & \multicolumn{2}{|c|}{$E u$} \\
\hline $505,9 \pm 30$ & 566,7 & 603,9 & $604,6 \pm 40$ & 632,5 & $\begin{array}{c}641,1 \pm 40 \\
623,9\end{array}$ & \multicolumn{2}{|c|}{547,7} \\
\hline \multicolumn{8}{|c|}{ б) yttrium subgroup } \\
\hline$G d$ & $T b$ & $D y$ & $\mathrm{Ho}$ & $E r$ & $T m$ & $Y b$ & $L u$ \\
\hline $552,6 \pm 30$ & 571,0 & 578,1 & 585,1 & $\begin{array}{c}598,4 \pm 40 \\
598,0\end{array}$ & 606,5 & 632,9 & $621,5 \pm 40$ \\
\hline
\end{tabular}
coefficient specifying dominating role of $4 \mathrm{f}$-electrons on $\Delta_{\mathrm{f}} \mathrm{H}^{0}{ }_{298}$ values of lanthanides' ions.

Table 1. Gaseous lanthanides' ion enthalpy formation

Experimental values for enthalpy formation $\left(\Delta_{\mathrm{f}} \mathrm{H}^{0}{ }_{298}, \mathrm{~kJ}\right.$ oule/mole) of some lanthanides' borohydrides $(L a, N d, S m, G d$ and Lu) [13-16] allowed to calculate current characteristics by equation (3) for the whole lanthanides' borohydrides series (table 2). Equation coefficient values (3) are equal to: $\alpha=-8,26 ; \beta=3,20 ; \gamma^{\prime}=-15,3$ and $\gamma^{\prime \prime}=0,30$.

Table 2. Standard values for $-\Delta_{\mathrm{f}} \mathrm{H}^{0}{ }_{298}(\mathrm{~kJ}$ oule/mole) of lanthanide's borohydrides 


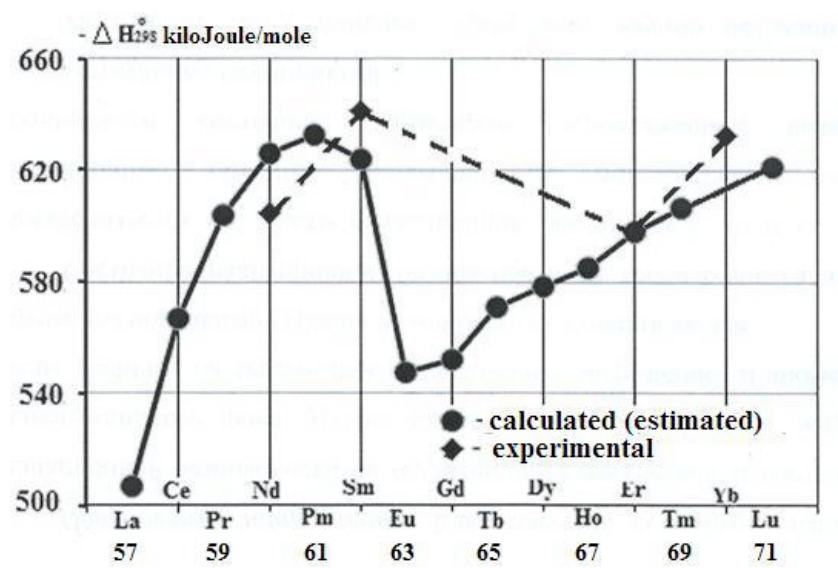

Figure 2. Borohydrides enthalpy formation - lanthonides atomic number diagram.

Lanthanide borohydride enthalpy formation - atomic number diagram curve (Fig.2) is complicated with tetrad-effect development. Sharp borohydrides' enthalpy formation value increase for cerium sub-group elements is observed as far as cainosimmetric $4 \mathrm{f}$ orbital are filled by electrons $\left(\mathrm{f}^{2}-\mathrm{f}^{6}\right)$. Sharp decrease of enthalpy formation value for europium borohydride is due to partial filling of $4 \mathrm{f}$ orbital by one electron and considerable influence of orbital motion moments of lanthanides' ion.

For yttrium subgroup borohydrides, starting from gadolinium, symbasis, almost linear increase of enthalpy formation values for lanthanides' borohydrides is observed with increase of $4 \mathrm{f}$-electrons number.

From Born-Haber cycle, $U_{\mathrm{K}}$ value of lanthanide borohydride is identified by the following equations:

$$
\begin{aligned}
& U_{k}\left[\operatorname{Ln}\left(B H_{4}\right)_{3}\right]=-\Delta_{f} H^{0}\left[\operatorname{Ln}\left(B H_{4}\right)_{3}\right]+S[L n]+6 D\left(H_{2}\right)+3 S[B]+ \\
& +I(L n)+3 E(H)-3 \delta\left[B H_{3}\right]=-\Delta_{f} H^{0}\left[\operatorname{Ln}\left(B H_{4}\right)_{3}\right]+\{S[L n]+I(L n)\}+ \\
& +6\left\{\frac{D}{2}\left(H_{2}\right)+E(H)\right\}+3 S[B]-3 \delta\left[B H_{3}\right]=-\Delta_{f} H^{0}\left[\operatorname{Ln}\left(B H_{4}\right)_{3}\right]+ \\
& +\Delta_{f} H^{0}\left(\operatorname{Ln}^{3+}\right)+3 \Delta H\left(H^{-}\right)-3 \delta\left[B H_{3}\right]=-\Delta_{f} H^{0}\left[\operatorname{Ln}\left(B H_{4}\right)_{3}\right]+ \\
& +\Delta_{f} H^{0}\left(\operatorname{Ln}^{3+}\right)+3 \Delta_{f} H^{0}\left(B H_{4}^{-}\right)
\end{aligned}
$$

$U_{K}$ calculation by equation (3) also is carried out, with

\begin{tabular}{|c|c|c|c|c|c|c|}
\hline \multirow{2}{*}{ Lanthanides } & \multirow{2}{*}{$\mathrm{r}, \AA$} & \multirow{2}{*}{$\Delta_{f} H_{298}^{0}$} & \multicolumn{4}{|c|}{$U_{K}$} \\
\hline & & & (2) & (1) & $\Delta, \%$ & (3) \\
\hline $\mathrm{La}$ & 1,16 & 506 & 3664,1 & 3811,09 & 7,5 & 3664,1 \\
\hline $\mathrm{Ce}$ & 1,14 & 567 & 3747,5 & 3788,56 & 3,7 & 3751,6 \\
\hline $\operatorname{Pr}$ & 1,13 & 604 & 3794,4 & 3840,22 & 3,1 & 3814,3 \\
\hline $\mathrm{Nd}$ & 1,12 & 615 & 3843,9 & 3850,02 & 1,5 & 3845,2 \\
\hline $\mathrm{Pm}$ & 1,09 & 632 & 3840,0 & 3879,75 & 1,9 & 3866,5 \\
\hline $\mathrm{Sm}$ & 1,08 & 632 & 3849,6 & 3889,76 & 2,0 & 3871,5 \\
\hline $\mathrm{Eu}$ & 1,07 & 548 & 3905,1 & 3899,82 & 0,8 & 3901,5 \\
\hline $\mathrm{Gd}$ & 1,05 & 553 & 3811,1 & 3920,10 & 3,6 & 3811,1 \\
\hline $\mathrm{Tb}$ & 1,04 & 571 & 3875,0 & 3930,32 & 2,3 & 3883,0 \\
\hline Dy & 1,03 & 578 & 3913,3 & 3940,59 & 1,8 & 3923,9 \\
\hline Ho & 1,02 & 585 & 3947,5 & 3950,92 & 1,8 & 3957,7 \\
\hline Er & 1,00 & 598 & 3971,4 & 3971,73 & 1,1 & 3984,5 \\
\hline $\mathrm{Tm}$ & 0,99 & 606 & 3996,2 & 3982,22 & 0,7 & 4004,3 \\
\hline $\mathrm{Yb}$ & 0,99 & 533 & 4047,8 & 3982,22 & 0,4 & 4057,0 \\
\hline $\mathrm{Lu}$ & 0,97 & 622 & 3998,8 & 4003,37 & 0,7 & 3998,8 \\
\hline
\end{tabular}
coefficients which is equal to $\alpha=23,91 ; \beta=-5,81 ; \gamma^{\prime}=15,7$ and $\gamma^{\prime \prime}=7,04 . \quad U_{K}$ calculation results by three independent methods are presented in table 3 .

Table 3. $\quad \Delta_{f} H_{298}^{0}(\mathrm{kJoule} / \mathrm{mole})$ values and Uк (kJoule/mole) of lanthanides borohydrides 
Specific features of lanthanides borohydrides thermochemical properties change is visually shown in Figure 3 within the group. It is necessary to notice that almost rectilinear character of this diagram is obtained according to Kapustinskiy equation which assumes purely ion nature of binding and considers only lanthanides' ion cation size change.

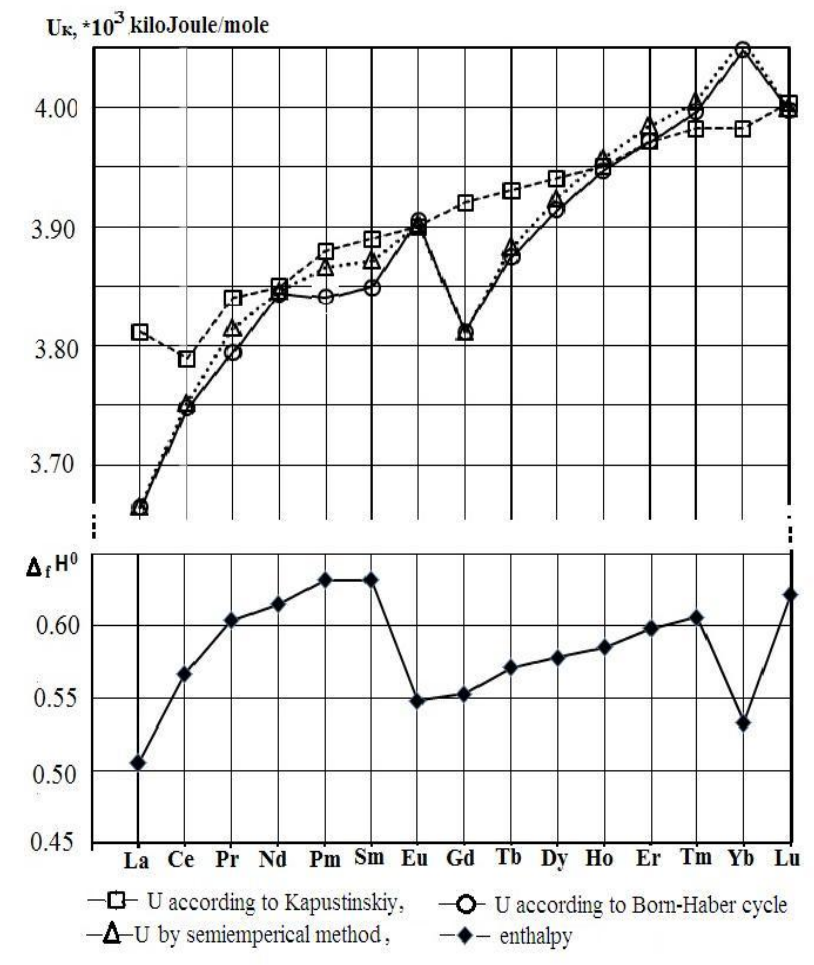

Figure 3. $U_{K}$ (a) and $\Delta_{f} H^{0}$ (b) dependence of borohydride from lanthanide atomic nuvber.

\section{Conclusions}

Thus, obtained results allowed to reveal the following features in thermochemical characteristics change of borohydrides:

a) with lanthanides atom nucleus increase charge:

- sybasis change and increase of enthalpy formation values and crystal lattice energy of lanthanides borohydrides is observed;

- diagrams of these curves have identical character with tetrad-effect development and with clear separation of lantanides' subgroups;

- characteristics deviation for europium and ytterbium compounds from general regularities due to their partial and full fillings by $4 \mathrm{f}$ orbital electrons of these elements atoms, extra stability in crystal field and spin-orbital interaction of 4-f-electrons.

b) $U_{K}$ values difference calculated by thermochemical cycle and Kapustinskiy formula indicates on certain fraction of covalent nature of chemical binding in borohydrides, by dominating character of ion binding. c) $U_{K}$ values coincidence, calculated by different methods for europium and ytterbium borohydrides indicates on purely ion character binding in compounds of these metals.

\section{REFERENCES}

[1] Bulletin A. Chemistry of solid state. Theory and attachments. P.1.- Moscow: Mir, 1988. -555 p.

[2] Novikov G.I. Basics of general chemistry. - M.: Visshaya Shkola, 1988. -431 p.

[3] Urusov V.S. Energy crystal chemistry. - M.: Nauka, 1975. $-335 \mathrm{p}$.

[4] Ormont B.F. Introduction to physical chemistry and crystal chemistry of semiconductors. - M.: Visshaya Shkola, 1973. $-234 \mathrm{p}$.

[5] Born M., Khuan Kun. Dynamic theory of crystalic lattice. - M.: IL, 1958. $-131 \mathrm{p}$.

[6] Sanderson, R.T. // Academic Press. 1976. - 321 p.

[7] Mirsaidov U.M. Borohydrides of transit metals / U.M. Mirsaidov, T.N. Dimova. - Dushanbe: Donish, 1985. - 125 p.

[8] Mirsaidov U.M. Thermal stability and thermodynamic characteristics of metal borohydrides / U.M. Mirsaidov, B.A. Gafurov, A. Badalov. - Dushanbe: Donish, 2014. - 107 p.

[9] Monograph: Physical and chemical properties of simple and complex hydrides of IA elements, II group and rare earth metals. Dushanbe, «Donish», 1994, 196p. Ikromov M. Mirsaidov M., Badalov A.

[10] Thermal stability and thermodynamic properties of gadolinium borohydrides. Coordination chemistry. 1992, v.18, Issue.3, p.333-336Mirsaidov U. Marufi V.K. Shaymurodov I.B. Ikramov M. Badalov A.

[11] Dimova T.N. // Proceedings of Academy of sciences of SSSR, chemistry series, 1973. -№12. -P.2661-2668.

[12] Isoev D.T. Thermodynamic and energetic characteristics of complex boro- and alumohydride elements IA and IIA groups: Author's abstract, dissertation for being $\mathrm{PhD}$ in Chemistry sciences - Dushanbe, 2000. -23 p.

[13] Segal, B.C. // Inorg. Chem. -1978. -V.17. -№4. -P.844-850.

[14] Belskiy B.K., Sobolev L.N., Bulichev B.M. and others // Coordination chemistry. -1990. -V.16. -№12. -P.1693-1697.

[15] Lobkovskiy E.B., Kravchenko S.E., Semenenko K.N. // Journal of structural chemistry. -1977. -V.18. -№2. P.389-391.

[16] Shaymurod I.B., Kurbonbekov A., Alikhanova T.Kh., Mirsaidov U.M. // Proceedings of Academy of sciences of SSSR, -1991. -№1. -P.32-36.

[17] Karapet'yanch M.K., Karapet'yanch M.L. Basics of thermodynamics constants of inorganic and organic substances. - M.: Chemistry, 1968. -470 p. 
[18] Thermal constants of substances. Reference book in 10 volumes. V.2, p.1. - M.: Academy of Sciences of SSSR, VINTI, IVT, 1978. -527 p. at the same place V.X, p.1, 1991, 229 p. at the same place V.X, p.2, 1991. -441 p.

[19] Volkov A.I., Zharskiy I.M. Big chemical reference book. -M. Modern school, 2005. -608 p.

[20] Lide D.R., Handbook of Chemistry and Physics, 84th Edition, CRC Press, Boca Raton, FL., 2003-2004/

[21] Poluektov N.S., Meshkova S.B., Korovin Y.B., Oksinenko I.I. // Doklady of Academy of Sciences of SSSR, 1982. -V.266. -№5. -P.1157-1160.

[22] Meshkova S.B., Poluektov N.S, Topilova Z.M., Danilkovich M.M. // Coordination chemistry, 1986. -V.12. -Issue.4. -P.481-484.
[23] Badalov A., Gafurov B.A., Mirsaidov I.U., Narulloev Kh., Mirsaidov U. // Journal of physical chemistry, 2014. -V.89. P.1103-1107.

[24] Thermodynamic characteristics of desolvation process for tetrahydridefuranate lanthanide, neodymium, samarium borohydrides, Coordination chemistry. 1992, V.18, issue 6, p.654-658. Mirsaidov U., Marufi F.K., Nazarov K.,Badalov A.

[25] Receipt, thermal stability and thermodynamic characteristics of lanthanum borohydride. Doklady Academy of Sciences of the Republic of Tajikistan 2003. №1-2, v.XLI , p.43-47. Islamova M.S. Gafurov B. A. Khakimov O., Badalov A.

[26] Thermodynamic characteristics of lanthanum borohydride. Doklady Academy of Sciences of the Republic of Tajikistan, 2002, v. XLV, №1,2, p.83-89. Mirsaidov U., Islamova M.S., Gafurov B.A., Badalov A. 